\title{
THE DYNAMICS OF TRICKLE INFECTIONS WITH HELIGMOSOMOIDES POLYGYRUS IN SYNGENEIC STRAINS OF MICE
}

\author{
T. J. BRAILSFORD and J. M. BEHNKE \\ MRC Experimental Parasitology Research Group, Department of Zoology, University of Nottingham, University Park, \\ Nottingham NG7 2RD, U.K.
}

(Received 4 April 1991; accepted 20 September 1991)

\begin{abstract}
Bralsford T. J. and Behnke J. M. 1992. The dynamics of trickle infections with Heligmosomoides polygyrus in syngeneic strains of mice. International Journal for Parasitology 22: 35I-359. NIH, CBA, SWR and C57Bl/10 mice were repeatedly infected with Heligmosomoides polygyrus, using doses of $10-$ 50 larvae at frequencies of 2-16 days. NIH and SWR mice regulated the worm burdens at a stable dosedependent level for a period of several weeks, following which expulsion occurred and immunity to subsequent re-infection was established. This regulation did not occur in CBA or C57Bl/10 mice, and was inhibited by cortisone treatment. Evidence was found to suggest that regulation is the result of an immune response directed against the late larval stages of the parasite, shortly after their emergence into the lumen of the gut. The frequency of infection was an important factor in determining the course of infection. Frequently infected mice expelled the parasites more rapidly than mice infected with the same total number of larvae in fewer less frequent doses.
\end{abstract}

INDEX KEY WORDS: Intestinal nematodes; Heligmosomoides polygyrus; trickle infection; repeated infection; immunity.

\section{INTRODUCTION}

UNDER natural conditions wild animals are exposed to parasitic infection at frequent intervals throughout their lives. In marked contrast to this, laboratorybased studies have generally exploited single pulsed primary and challenge infections. This simplification of the complex ecological relationships that occur between hosts and parasites is essential in the study of immunological aspects of parasitic disease. However caution is warranted before extrapolation to events in the field, where continuous small dose exposure may generate a quite different interaction. Long-term trickle infection regimes whilst more laborious and difficult to control, provide a more realistic simulation of naturally occurring events and have been shown to provide data essential to modelling the epidemiology of important parasitic diseases (Crombie \& Anderson, 1985).

Much of the published data on trickle infections with nematode parasites has involved the use of sheep and cattle. Domestic animals, usually restrained from foraging freely and often forced to graze on permanent pasture, are particularly at risk from repeated infections. Laboratory studies have exploited Nippostrongylus brasiliensis, Trichuris muris and recently Heligmosomoides polygyrus. All of these studies have drawn attention to the contrast in infection dynamics following trickle exposure with those of the more conventional single pulse regimes. In $N$. brasiliensis, trickle infections result in prolonged fecund infections only in young rats where the complication of neonatal unresponsiveness has to be considered (Jenkins \& Phillipson, 1970, 1972). In T. muris trickle infections a small number of adults become established from the initial inocula, but none do thereafter (Wakelin, 1973; Behnke \& Wakelin, 1973). However H. polygyrus has provided a pattern quite different to either $N$. brasiliensis or $T$. muris (Brindley \& Dobson, 1982; Slater \& Keymer, 1986; Maema, unpublished $\mathrm{PhD}$ thesis, Imperial College, University of London, 1986). This parasite causes chronic primary infections that last for many months, and under trickle infection regimes worm burdens accumulate during the first weeks of infection. In some strains of mice lethal burdens eventually develop, but in others regulatory mechanisms are invoked and the parasite numbers stabilize or decline (Keymer \& Slater, 1990). It is evident from published data that the regulation of $H$. polygyrus varies considerably between different strains of micc, and the protocols that have been employed to date have not evaluated all of the critical factors. 

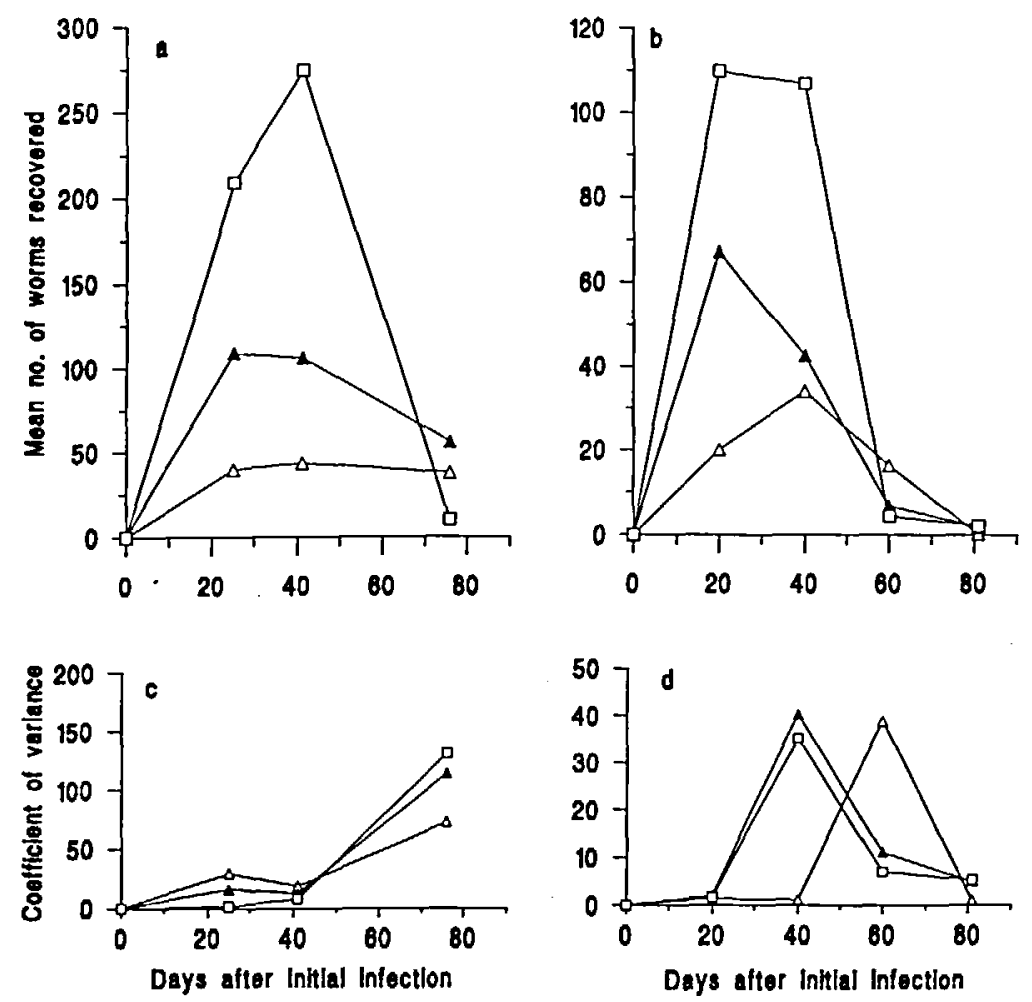

FIG. 1. Adult worms recovered from NIH mice during the course of trickle infection with H. polygyrus. Experiment $1(\mathrm{a}, \mathrm{c})$ consisted of groups of three to four mice infected with $10(\Delta), 25(\Delta)$ or $50(\square)$ larvae twice per week, and Experiment $2(b, d)$ consisted of groups of six to eight mice infected with $10(\Delta), 30(\Delta)$ or $50(\square)$ larvae twice per week. Values are given as mean worm burden $(a, b)$ and coefficient of variance $(c, d)$ for each group of mice. 'Tracer' controls showed mean primary infectivities of $78.8 \pm 11.2 \%$ and $86.7 \pm 5.6 \%$, respectively.

In this paper we report on trickle infection regimes in syngeneic mouse strains selected to represent strong and weak responding phenotypes on the basis of previously published work (Behnke \& Robinson, 1985). Immunosuppression is used to determine the pattern of events in the absence of a fully functional immune system and the principal variables (i.e. dose and frequency of infection) are investigated to ascertain their relative importance in the infection dynamics of the parasite.

\section{MATERIALS AND METHODS}

Parasile. The Wellcome strain of H.polygyrus (H.p.bakeri, Durette-Desset, Kinsella \& Forrester, 1972) was used for this study, and was maintained as described by Behnke \& Robinson (1985). The mice were infected intragastrally with a $0.2 \mathrm{ml}$ inoculum using a blunt needle. To test the infectivity of the larvae used for trickle infections, a few 'tracer' controls were set up at several points throughout each experiment. These consisted of primary infections with
100 larvae, and the worms were counted at autopsy usually 21 days post-infection. Adult worms were recovered by slitting the small intestine longitudinally and incubating gut tissues and contents in a mesh in Hank's saline at $37^{\circ} \mathrm{C}$ for about $2 \mathrm{~h}$. The intestine was then squashed between two sheets of glass and any larvae present in the mucosa were counted under a dissecting microscope. Faeces were collected over a $24 \mathrm{~h}$ period and the method described by Jackson (1974) was used to quantify the epg of faeces.

Host. Inbred female mice of the NIH, CBA, SWR and C57 strains were used in this study. All animals were dosed with $0.2 \mathrm{ml}$ of $20 \mathrm{mg} \mathrm{ml}^{-1}$ piperazine citrate 2 weeks and again at 1 week prior to the start of the experiment. Hydrocortisone was administered subcutaneously, each animal receiving 0.2 $\mathrm{ml}$, containing $25 \mathrm{mg} \mathrm{ml}^{-1}$.

Statistical analysis. Worm burdens are presented as group mean worm recovery $(M W R) \pm$ standard error (S.E.M.). Where required, data were analysed using the unified ranking system described by Meddis (1984) to test specific a priori hypotheses. 


\section{EXPERIMENTAL DESIGN AND RESULTS}

The influence of infection doses (Experiments 1 and 2)

Groups of NIH mice were exposed to varying doses of larvae twice weekly in two separate experiments (Experiments 1 and 2). Mice were given 10, 25 or 50 (Experiment 1) and 10,30 or 50 (Experiment 2) larvac and were killed in groups of three to four (Experiment 1) or seven to eight (Expcriment 2) at regular intervals as shown in Fig. 1. In Experiment 2 autopsies were carried out 4 days after the previous infection, timed to coincide with the development of L4 stages, thereby enabling tissue larval burdens to be evaluated.

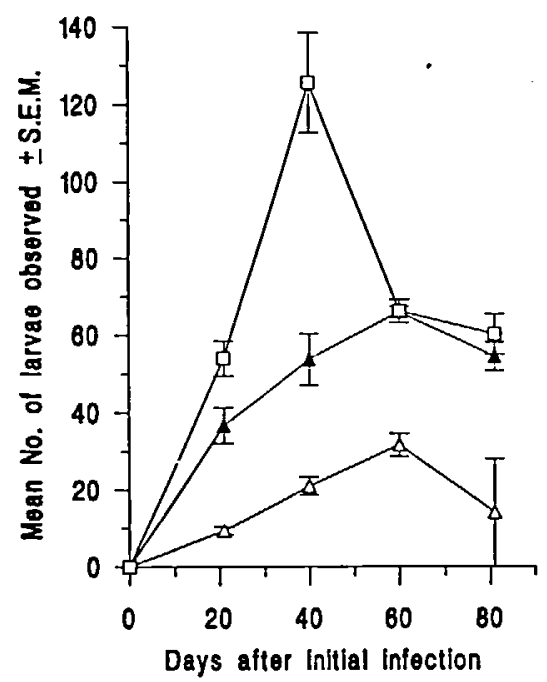

Fig. 2. The number of larvae of $H$. polygyrus observed in the intestinal walls during the course of trickle infection; Experiment 2 , infected with $10(\Delta), 30(\Delta)$ or $50(\square)$ larvae twice per week.

During the course of trickle infections with $H$. polygyrus the adult worm burdens increased rapidly to a peak, by about 3 weeks after the initial exposure. Worm burdens then remained relatively stable for 4-6 weeks, after which there was a rapid loss of the adult parasites (Fig. 1). The plateau was dose dependent, varying from well over 100 worms in mice infected with $50 \mathrm{~L} 3$ twice weekly to about 30 in mice infected with only 10 L3. Expulsion of worms was more rapid in the heavily infected mice, but by 80 days after the initial infection there was little to distinguish between the groups. The a priori hypothesis of dose dependence was significant at day 21 ( $L=414, Z=3.89$, $P=0.0001)$, and at day $40(L=278, Z=1.95, P=0.0256)$, but not on day $60(L=335, Z=0.36)$, or day 80 $(L=354 ; Z=0.86)$. During the early and late stages of the experiment, worm burdens were fairly consistent within the groups as is shown by the coefficient of variance plots in Fig. 1, but during the period of expulsion variation between individuals increased as some mice expelled worms much faster than others. This increase in variability occurred later in the animals given the lowest dose, again suggesting a dose dependence in the timing of expulsion. Larval stages counted in the intestines of these mice also increased during the course of the experiment in a dosedependent manner (Fig. 2), but there was no sig-
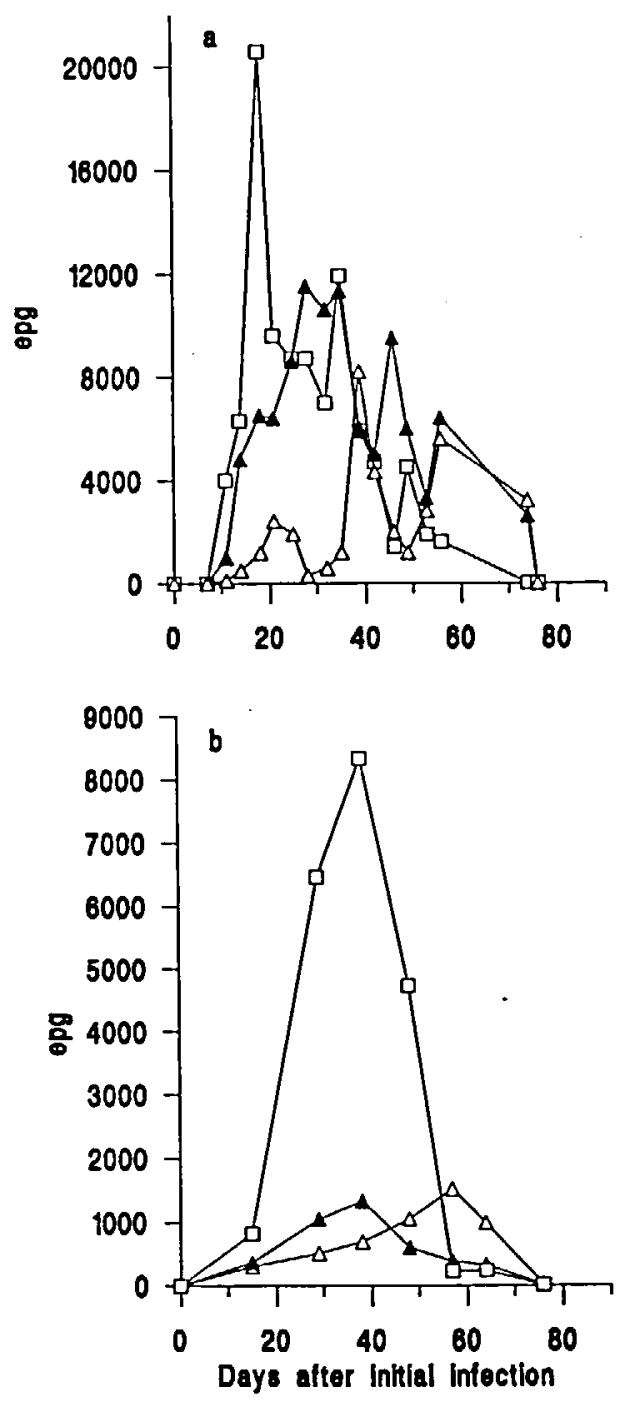

FIG. 3. Egg counts from NIH mice exposed to trickle infection with $H$. polygyrus. Experiment 1 (a) consisted of groups of three to four mice infected with $10(\triangle), 25(\Delta)$ or 50 () larvae twice per week, and Experiment 2 (b) consisted of groups of six to eight mice infected with $10(\Delta), 30(\Delta)$ or 50 ( $\square$ ) larvae twice per week. The values given are the egg counts of faeces pooled for each group. 
nificant reduction of numbers during the later stages of the experiment (for mice infected with $10 \mathrm{~L} 3, H=16.49$, $P=0.6360$; with $30 \mathrm{L3}, H=12.53, P=0.6758$; and with $50 \mathrm{~L} 3, H=12.19, P=0.6781$ ). Egg counts for these experiments are shown in Fig. 3, and these closely reflect the adult worm burdens.

Trickle infection in immunosuppressed mice (Experiments 3 and 4)

Two experiments were carried out to determine the course of trickle infection in mice treated with the immunosuppressive drug hydrocortisone. NIH mice were infected twice weekly with a single dose of 25 larvae using groups of three to four mice (Experiment 3 ), and this was repeated with a dose of 30 larvae using groups of seven to eight mice (Experiment 4).

During immunosuppression adult worm burdens resulting from trickle infections increased for the duration of the experiment with no expulsion of worms being evident (Fig. 4). Statistical analysis showed that cortisone did not result in higher worm burdens on day $30(L=53.5, Z=0.13)$ or day 45 ( $L=54, Z=0.19$ ), but that on day 60 therc was a highly significant difference $(L=76.0, Z=3.01$, $P=0.0016$ ). Immunosuppression did not affect the number of larvae found in the intestine, which remained fairly constant in all the groups in this experiment, with $M W R$ in the range $39.7 \pm 4.9$ $44.1 \pm 2.6$. Egg counts in the cortisone-treated groups were considerably higher than those of the untreated controls (Fig. 5) at all but the earliest stages of patency, even when there were no differences in the numbers of adult worms present.

Trickle infection in strong and weak responding mouse strains (Experiments 5 and 6)

Four mouse strains, selected for their contrasting responses to $H$. polygyrus in primary and secondary infections, were dosed twice weekly. In Experiment 5 groups of three to four NIH, C57 and SWR mice were infected with doses of 25 larvae, and in Experiment 6 groups of seven to eight NIH and CBA mice were infected with doses of 30 larvae. NIH and SWR mice were found to exhibit the patterns described above, that is an initial increase in adult worm burdens followed by a period of stability and finally expulsion (Fig. 6). In the cases of $\mathrm{CBA}$ and $\mathrm{C} 57 \mathrm{Bl} / 10$ mice, however, worms continued to accumulate throughout the course of the experiments. Faecal egg counts from these mice reflected the number of adult worms present (Fig. 7).

\section{Immunity induced by trickle infection (Experiment 7)}

In Experiment 7 groups of seven to eight NIH mice were infected twice weekly with 10,30 or 50 larvae for
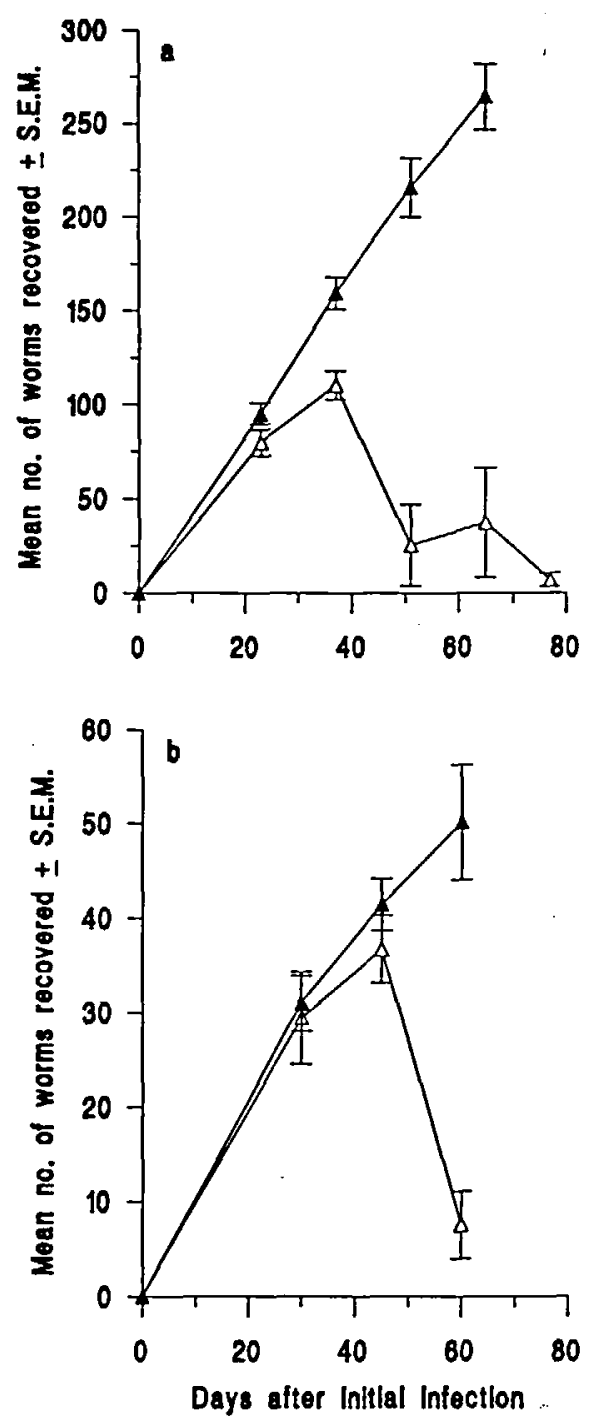

Fig. 4. Adult $H$. polygyrus recovered from NIH mice infected with 25 larvae twice weekly and either treated (A) or not treated $(\Delta)$ by subcutaneous injection of $0.2 \mathrm{ml} 25 \mathrm{mg} \mathrm{ml}^{-1}$ hydrocortisone twice weekly. Experiment 3 (a) used groups of two to four mice, and Experiment 4 (b) used groups of seven mice. 'Tracer' controls showed mean primary infectivities of $87.3 \pm 3.9 \%$ and $93.2 \pm 4.9 \%$, respectively.

10 weeks. Half of each group was then rested for 4 weeks while regular infections of the remainder were continued. All the groups and also an age matched naive group were then challenged with 100 larvae, and killed 21 days post-challenge. The results clearly demonstrate that all three trickle infection doses induced a long lasting immunity to subsequent challenge as reflected in low burdens recovered at autopsy, 

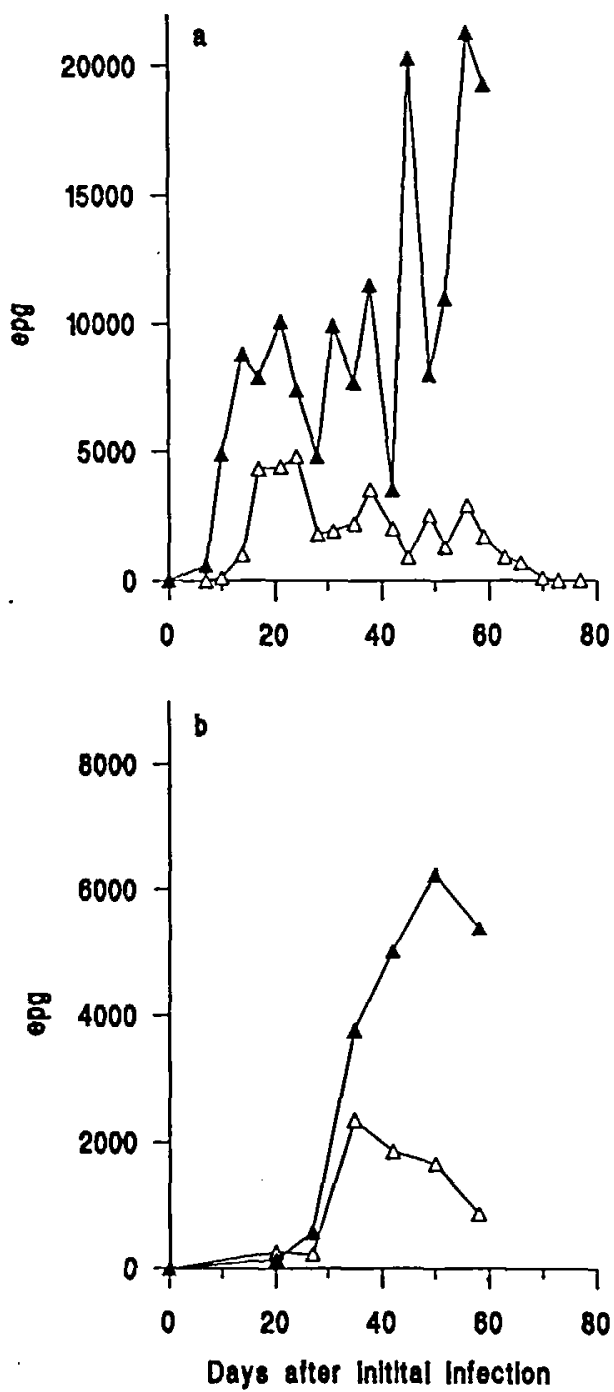

FIG. 5. Egg counts of NIH mice exposed to trickle infection with $H$. polygyrus and treated $(\boldsymbol{\Delta})$ or not treated $(\Delta)$ with cortisone in Experiments 3 (a) and 4 (b). The values given are the egg counts of faeces pooled for each group.

regardless of whether or not trickle exposure was maintained during the 4 weeks prior to challenge with 100 L3 (Table 1).

The effects of varying the time intervals between infections (Experiment 8)

Groups of seven to eight NIH mice were infected with a total of 100 larvae during each successive 16 day period. These were given as eight doses of about 12 larvae (protocol A) or as four doses of 25 larvae (protocol B) or as two doses of 50 larvae (protocol C) or as a single dose of 100 larvae (protocol D). Thus in
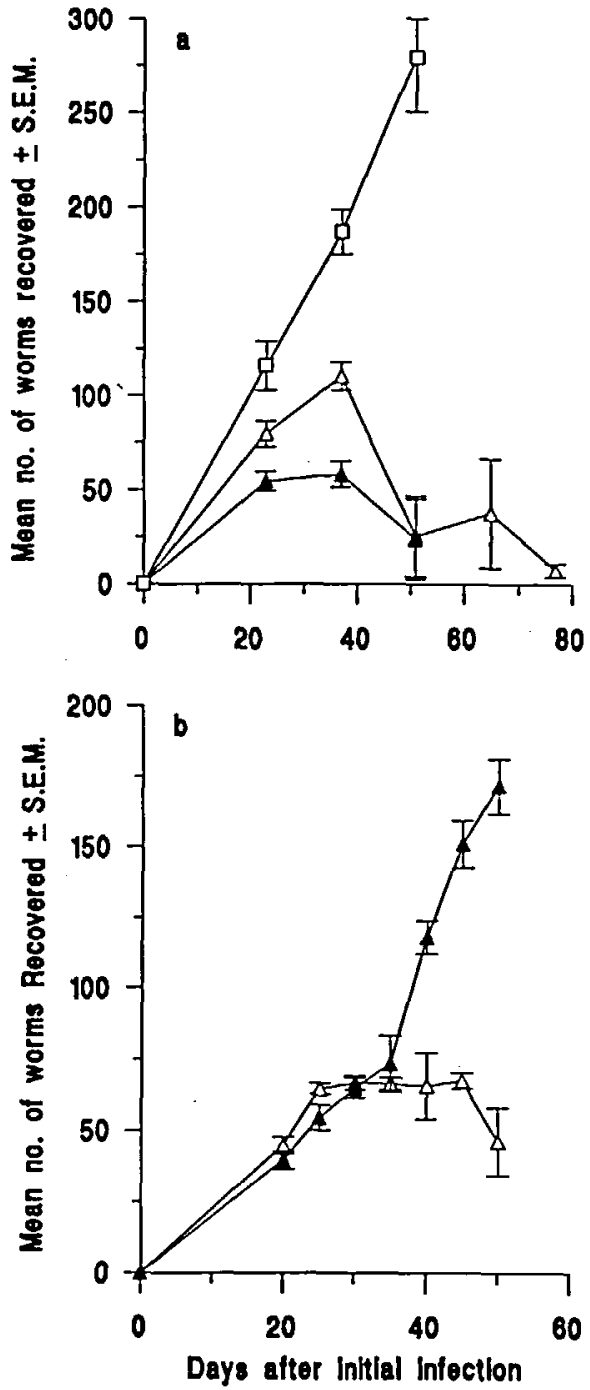

Fig. 6. Adult worms recovered from groups of two to four $\operatorname{NIH}(\triangle), C 57(\square)$ and SWR $(\Delta)$ mice [Experiment 5(a)] and groups of $10 \mathrm{NIH}(\triangle)$ and $\mathrm{CBA}(\Delta)$ mice [Experiment $6(\mathrm{~b})$ ] following twice weekly infections with 25 and 30 larvae, respectively. 'Tracer' controls showed mean primary infectivities of $87.3 \pm 3.9 \%$ and $89.2 \pm 3.5 \%$, respectively.

each 16 day cycle the total number of larvae to which the animals were exposed remained constant, with only the interval between infections varying. This experimental design is shown in Table 2. When the time between infections was varied a considerable effect upon the adult worm burdens was observed (Fig. 8). In mice infected every 2 days (protocol A), peak worm burdens were detected at 24 days after the initial infection, and expulsion occurred at 32-40 days. In the less frequently infected groups (protocols B and C) 

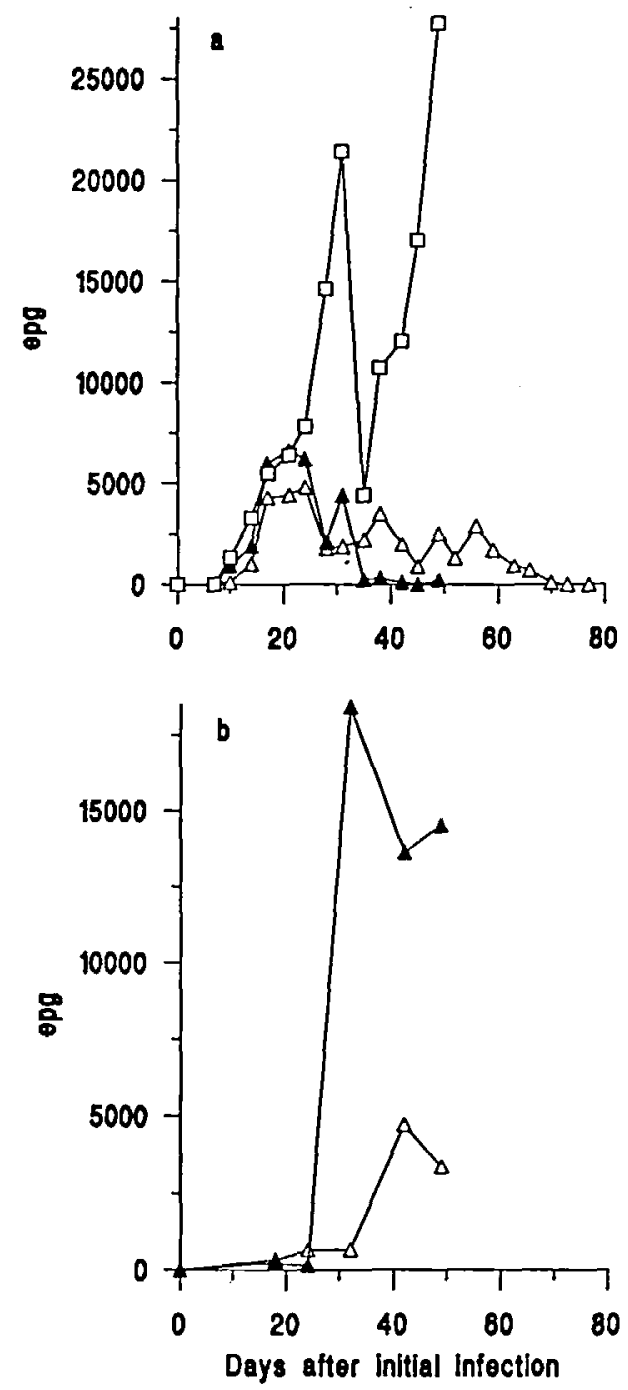

Fig. 7. Egg counts for NIH $(\Delta), C 57(\square)$ and SWR ( $\Delta)$ [Experiment 5(a)] and NIH $(\triangle)$ and CBA $(\Delta)$ [Experiment 6(b)], exposed to trickle infection with $H$. polygyrus. The values given are the egg counts of faeces pooled for each group.

both the peak worm burden and the cxpulsion occurred later. In the least frequently infected mice infected only once every 16 days (protocol D) there was no detectable loss of adult worms during the course of the experiment.

\section{DISCUSSION}

One of the most important conclusions to be drawn from this study is that the frequency of infection with H. polygyrus had a marked influence on the course of subsequent events. This is an aspect of trickle

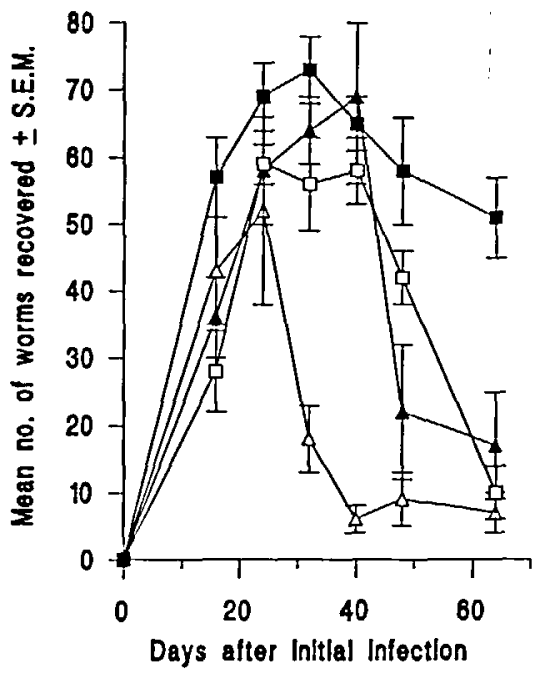

FIG. 8. The effect of varying the interval between infection on adult worm burdens developing in NIH mice. Groups of seven to nine NIH mice (Experiment 7) were infected using protocol $A(\Delta)$, protocol $B(\Delta)$, protocol $C(\square)$, or protocol $D$ ( $\boldsymbol{B})$ - see Table 2 for an explanation of the infection protocols. 'Tracer' controls showed a mean primary infectivity of $93.7 \pm 6.4 \%$.

infections that has not been investigated previously. Maema (1986, thesis cited above) used weekly infections whereas Slater \& Keymer (1986) infected mice every 2 weeks. It has already been established that as few as $10 \mathrm{H}$. polygyrus can induce virtually solid resistance to challenge infections in NIH mice, provided that no adult worms are allowed to develop (Behnke \& Robinson, 1985; Wahid \& Behnke, in press). This latter point is most important and it is highly relevant to the present work, in that the higher worm burdens that were developed during the early stages of infection in those mice that were infected less frequently but with higher doses, would have exerted a pronounced immunomodulatory effect on the development of immunity. Mice given lower doses at more frequent intervals probably developed immunity more rapidly because they had fewer adult worms from the outset and they were more often subjected to stimulation by larvae. An expulsion response could therefore be invoked at an earlier stage than in less frequently infected animals.

The second important point which we wish to emphasize is that the host response appcared to act against the late larval or early pre-adult stages, immediately after their emergence from the tissue stage of development. This conclusion was reached because in immune mice L3 initially became established, and no evidence was found to suggest that 
TABle 1 -Recovery of adULt $H$. polygyrus fRoM NIH MICE 21 Days AFter CHALlENGE INAFECTION WITH 100 L3 (EXPERINIENT 7)

\begin{tabular}{|c|c|c|c|}
\hline \multirow{2}{*}{$\begin{array}{l}\text { Immunizing } \\
\text { infections, dose of } \\
\text { L3 administered } \\
\text { (twice weekly) }\end{array}$} & & \multicolumn{2}{|c|}{$\begin{array}{c}\text { Challenge infection } \\
\text { (mean number of worms recovered } \\
\pm \text { S.E.M.) }\end{array}$} \\
\hline & . & Continuous infection & Rested \\
\hline 10 & & $3.43 \pm 1.25$ & $0.5 \pm 0.34$ \\
\hline 30 & & $0.67 \pm 0.33$ & $1.0 \pm 0.82$ \\
\hline 50 & & $0.33 \pm 0.21$ & $0.67 \pm 7.72$ \\
\hline Naive & & - & $92.83 \pm 7.72$ \\
\hline
\end{tabular}

TABLE 2-INFECTION PROTOCOL FOR EXPERIMENT 8; ANIMALS NERE KILLED ON DAYS $16,24,32,40,48$ AND 64 OF THE EXPERIMENT

\begin{tabular}{|c|c|c|c|c|}
\hline \multirow[b]{2}{*}{ Day } & \multicolumn{4}{|c|}{ Infection protocol } \\
\hline & $\begin{array}{c}\text { Protocol A } \\
12 \mathrm{~L} 3\end{array}$ & $\begin{array}{c}\text { Protocol B } \\
25 \mathrm{~L} 3\end{array}$ & $\begin{array}{c}\text { Protocol C } \\
50 \mathrm{~L} 3\end{array}$ & $\begin{array}{l}\text { Protocol D } \\
100 \mathrm{L3}\end{array}$ \\
\hline 1 & $\mathrm{x}$ & $\mathrm{x}$ & $\mathrm{x}$ & $\mathrm{x}$ \\
\hline 2 & & & & \\
\hline 3 & $\mathrm{x}$ & & & \\
\hline 4 & & & & \\
\hline 5 & $\mathrm{x}$ & $\mathrm{x}$ & & \\
\hline 6 & & & & \\
\hline 7 & $\mathrm{x}$ & & & \\
\hline 8 & & & & \\
\hline 9 & $\mathrm{X}$ & $\mathrm{x}$ & $\mathrm{x}$ & \\
\hline 10 & & & & \\
\hline 11 & $\mathrm{x}$ & & & \\
\hline 12 & & & & \\
\hline 13 & $\mathrm{X}$ & $\mathrm{x}$ & & \\
\hline 14 & & & & \\
\hline 15 & $\mathrm{x}$ & & & \\
\hline 16 & & & & \\
\hline
\end{tabular}

worms were killed during the tissue phase, and L4 and immature adults were never recovered during these late stages of trickle infection. This interpretation is consistent with the conclusions arrived at by Cypess, Lucia, Dunsford \& Enriquez (1988) and Ey (1988) when analysing the expression of acquired immunity in immune mice. In our experiments all inocula established and were found to give constant tissue larval counts which were dose dependent. However, since adult burdens were stable in the period before expulsion, larvae must have been continually lost before contributing to the adult worm population. Alternatively there may have been a turnover of adult worms, but we feel this is unlikely because once infections developed to the plateau phase juvenile adults were not encountered in the gut lumen. We interpret our results as indicating that there is little or no antiestablishment immunity. The success of larvae given during the plateau phase of infection is curtailed shortly after their emergence into the intestinal lumen. Adult worms continue to maintain themselves for a longer period of time, as occurs in $H$. contortus and $T$. vitrinus, until the host becomes resistant to their immunomodulatory activity, thereby allowing the expression of an anti-adult worm response with the consequent expulsion of the established worms.

At least two distinct regulatory mechanisms appear to operate to limit worm burdens in animals subjected to trickle infections with gastro-intestinal nematode parasites. Calves dosed daily with Ostertagia ostertagi and sheep with $O$. circumcincta limit infection by a continual turnover of adult worms which, in combination with a gradual decrease in the proportion of new larvae that become established, results in the development of a dose-dependent equilibrium (Michel, 1969, 1970; Waller \& Thomas, 1978). In 
contrast to this, sheep exposed daily or weekly to Haemonchus contortus show a linear dose-dependent accumulation of worms, followed by a plateau during which time only adult worms can be recovered. This stage is then followed by a rapid loss of the adult worms, particularly in the animals receiving the highest doses (Christie, Brambell \& Charleston, 1964; Barger, Le Jambre, Georgi \& Davies, 1985). The regulation of $H$. contortus appears to be due largely to the inhibition of larval establishment, and there is no evidence to suggest that any significant degree of turnover occurs. Trichostrongy'lus colubriformis and $T$. vitrinus in sheep and T. axei in cattle have also been found by Donald \& Waller (1982) and Jackson, Angus \& Coop (1983) to be regulated in a manner similar to that of Haemonchus.

In this study $H$. polygyrus was found to be regulated by means distinct from either of those described above but closer to the Haemonchus and Trichostrongylus systems than to that of Ostertagia. The principal distinction was the continual success of larval parasites in establishing even at a time at which adult worms were no longer accumulating. However not all strains of mice were capable of regulating the infections. NIH and SWR mice were both found to regulate worm numbers as described above, but CBA and $\mathrm{C} 57 \mathrm{Bl} / 10$ did not regulate parasite burdens, and continued to accumulate worms throughout the course of the study. The main effectors of protective immunity to $H$. polygyrus are believed to be eosinophils and IgE, under the influence of IL4 and possibly IL5 (Urban, Katona, Paul \& Finkelman, 1991). This protective immunity to $H$. polygyrus is known to be subject to genetic variation, and worm survival is dependent upon $\mathrm{H}-2$ linked genes (Behnke \& Wahid, 1991). Since it is well known that NIH and SWR mice are strong responding strains to $H$. polygyrus, and $\mathrm{CBA}$ and $\mathrm{C} 57 \mathrm{BI} / 10$ are weak responders (Prowse \& Mitchell, 1980; Behnke \& Robinson, 1985; Enriquez, Scarpino, Cypess \& Wassom, 1988), the immune regulation of $H$. polygyrus trickle infections must thus be subject to similar genetic control to that observed in single pulse infections.

It thus seems that repeated infection with Heligmosomoides polygyrus results in an immunologically based and thus genetically controlled regulation of the parasite load. In animals of the appropriate genotype continuing infection ultimately leads to the expulsion of most adult worms and the establishment of a strong protective immunity directed primarily against the late L4 or early preadult stages. This regulation and immunity is dependent upon the dose of infective larvae at each infection and the time in between infections, and these are likely to be phenomena of some epidemiological importance.
Acknowledgement-We are most grateful to Professors D. Wakelin and P. N. R. Usherwood for the provision of facilities in the Nottingham University Zoology Department. We should also like to thank Mr M. John for carrying out some of the early experiments in this study, and $\mathrm{Mr} \mathrm{K}$. Cosgrove and his staff for the maintenance of the experimental animals. This work was conducted during the tenure of an MRC training fellowship (TJB).

\section{REFERENCES}

Barger I. A., Le Jambre L. F., Georgi J. R. \& Davies H. I. 1985. Regulation of Haemonchus contortus populations in sheep exposed to continuous infection. International Journal for Parasitology 15: 529-533.

BeHNike J. M. \& WAKELIN D. 1973. The survival of Trichuris muris in wild populations of its natural host. Parasitology 67: 157-164.

Behnike J. M. \& Robinson M. 1985. Genetic control of immunity to Nematospiroides dubius : a 9-day anthelmintic abbreviated immunizing regime which separates weak and strong responder strains of mice. Parasite Immunology 7 : 235-253.

BEHNKE J. M. \& WAHID F. N. 1991. Immunological relationships during primary infection with Heligmosomoides polygyrus (Nematospiroides dubius): H-2 linked genes determine worm survival. Parasilology 103: 157164.

Brindey P. J. \& Dobson C. 1982. Multiple infections with Nematospiroides dubius in mice selected for liability to a single infection. Australian Joturnal of Experimental Biology and Medical Science 60: 319-327.

Christie M. G., Brambell M. R. \& Charleston W. A. G. 1964. Worm populations in young sheep dosed daily with 10,000 larvae of Haemonchus contortus. Journal of Comparative Pathology. 74: 435-446.

Crobe J. A. \& Anderson R. M. 1985. Population dynamics of Schistosoma mansoni in mice repeatedly exposed to infection. Nature (London) 315: 491-493.

Cypess R. H., Lucia H. L., Dunsford H. A. \& Enriquez F. J. 1988. The tissue reaction of mice infected with $\mathrm{He}$ igmosomoides polygyrus. Journal of Helminthology 62: 6972.

Donald A. D. \& Waller P. J. 1982. Problems and prospects in the control of helminthiasis in sheep. In: Biology and Control of Endoparasites (Edited by Symons L. E. A., Donald A. D. \& Dineen J. K:). Academic Press, Sydney

Durette-Desset M., Kinsella J. M. \& Forrester D. J. $197 \overline{9} 2$. Arguments en faveur de la double origine des Nématodes néarctiques du genre Heligmosomoides Hallm, 1916. Annales de Parasotologie Humaine et Comparé 47: 365-382.

Enriquez F. J., Scarpino V., Cypess R. H. \& Wassom D. L. 1988. In vivo and in vitro egg production by Nematospiroides dubius during primary and challenge infections in resistant and susceptible strains of mice. Journal of Parasitology 74: 262-266.

Ey P. L. 1988. Heligmosomoides polygyrus: excretory/secretory antigen released in vitro by exsheathed third-stage larvae. Experimental Parasilology 67: 210-220.

JACKson F. 1974. New technique for obtaining nematode ova from sheep faeces. Laboratory Practice 23: 65-66. 
JaCkson F., ANgus K. W. \& Coop R. L. 1983. Development of morphological changes in the small intestine of lambs continuously infected with Trichostrongylus vitrinus. Research in Veterinary Science 34: 301-304.

Jenkins D. C. \& Phillipson R. F. 1970. The kinetics of repeated low level infections of Nippostrongylus brasiliensis in the laboratory rat. Parasitology 62: 457-465.

Jenkins D. C. \& Phillipson R. F. 1972. Increased estab. lishment and longevity of Nippostrongylus brasiliensis in immune rats given repeated small infections. International Journal for Parasitology 2: 105-111.

Keymer A. E. \& Slater A. F. G. 1990. Animal models and epidemiology. In: Hookworm Disease. Current Status and New Direction (Edited by Schad G. A. \& Warren R. S.). Taylor \& Francis, London.

MEDDis R. 1984. Statistics Using Ranks, A Unified Approach. Blackwell, Oxford.

Michel J. F. 1969. Some observations on the worm burdens of calves infected daily with Ostertagia ostertagi. Parasitology 59: 575-595.

Michel J. F. 1970. The regulation of populations of Ostertagia ostertagi in calves. Parasitology 61: 435-447.

Prowse S. J. \& Mitchell G. F. 1980. On the choice of mice for dissection of strain variations in the development of resistance to infection with Nematospiroides dubius. Australian Journal of Experimental Biology and Medical Science 58: 603-605.

Slater A. F. G. \& Keymer A. E. 1986. Heligmosontoides polygyrus (Nematoda): the influence of dietary protein on the dynamics of repeated infection. Proceedings of the Royal Society, London, Series B 229: 69-83.

Urban J. F., Katona I. M., Paul W. E. \& Finkelman F. D. 1991. Interleukin 4 is important in protective immunity to a gastrointestinal nematode infection in mice. Proceedings of the National Academy of Science of the United States of America 88: 5513-5517.

Wahid F. N. \& BenNike J. M. (in press) Heligntosomoides polygyrus (Nematospiroides dubius): intestinal tissue resident $\mathrm{L} 3$ and $\mathrm{L} 4$ larvae both provide key stimuli for acquired resistance. Experimental Parasitology.

WAKELIN D. 1973. The stimulation of immunity to Trichuris muris in mice exposed to low-level infections. Parasilology 66: 181-189.

Waller P. J. \& Thomas R. J. 1978. Nematode parasitism in sheep in Northeast England. The epidemiology of Ostertagia species. International Journal for Parasitology 8: 275-283. 